\author{
А. М. Митренков, О. В. Бахур \\ Белорусский государственный технологический университет
}

\title{
ОЦЕНКА ВЛИЯНИЯ КОПЫТНЫХ ЖИВОТНЫХ ПРИ ВОЛЬЕРНОМ СОДЕРЖАНИИ НА СОСТОЯНИЕ КОМПОНЕНТОВ ЛЕСНЫХ НАСАЖДЕНИЙ
}

\begin{abstract}
В статье рассматривается влияние оленя благородного (Cervus Elaphus L., 1758) на компоненты лесных насаждений. Цель исследований - оценка состояния нижних ярусов лесных насаждений на территории вольеров для передержки в зависимости от времени, прошедшего с момента выпуска животных. Проведенные исследования показали, что при содержании копытных животных в вольерах для передержки оказывается значительное негативное влияние на все компоненты лесных насаждений и особенно на подлесок и подрост как лиственных, так и хвойных пород. Повреждения, нанесенные животными, могут в дальнейшем способствовать поражению растений грибковыми заболеваниями. Из-за чрезмерной кормовой нагрузки наблюдается выпадение из состава подроста сосны обыкновенной. С течением времени после выпуска животных в угодья наблюдается постепенное восстановление подпологовой растительности, в том числе и кустарничкового яруса, что проявляется через увеличение его проективного покрытия. Наблюдается также зарастание ранее проложенной животными тропиночной сети, минерализации почвы и снижение плотности верхнего горизонта.
\end{abstract}

Ключевые слова: вольер для передержки, насаждение, подрост, подлесок, живой напочвенный покров, олень благородный.

Для цитирования: Митренков А. М., Бахур О. В. Оценка влияния копытных животных при вольерном содержании на состояние компонентов лесных насаждений // Труды БГТУ. Сер. 1, Лесное хоз-во, природопользование и прераб. возобновление ресурсов. 2022. № 1 (252). С. 87-92.

\author{
A. M. Mitrenkov, A. V. Bakhur \\ Belarusian State Technological University
}

\section{ASSESSMENT OF THE IMPACT OF HOOFED ANIMALS IN THE ENCLOSURE ON THE STATE OF THE COMPONENTS OF FOREST PLANTATIONS}

The article examines the influence of the red deer (Cervus Elaphus L., 1758) on the components of forest plantations. The purpose of the research is to assess the living condition of forest plantations on the territory of overexposure enclosures, depending on the time that has passed since the release of livestock. The conducted studies have shown that when keeping ungulates in overexposure enclosures, there is a significant negative impact on all components of forest plantations, and especially on undergrowth and undergrowth, both deciduous and coniferous species. Damage caused by animals can further contribute to the defeat of plants by fungal diseases. Due to excessive feed load, loss of the undergrowth of the common pine is observed. Over time, after the release of animals into the grounds, there is a gradual restoration of the sub-ecological vegetation, including the shrub layer, which is manifested through an increase in its projective coverage. There is also an overgrowth of the path network previously traversed by animals and a decrease in the density of the upper soil horizon.

Key words: aviary for overexposure, stocking, underbrush, subgenus, field layer, red deer.

For citation: Mitrenkov A. M., Bakhur A. V. Assessment of the impact of hoofed animals in the enclosure on the state of the components of forest plantations. Proceedings of BSTU, issue 1, Forestry. Nature Management. Processing of Renewable Resources, 2022, no. 1 (252), pp. 87-92 (In Russian).

Введение. В соответствии с мероприятиями подпрограммы 3 государственной программы «Белорусский лес» с 2016 по 2020 г. на территориях более 70 охотничьих хозяйств были выпущены около 5 тыс. особей оленя благородного (Cervus Elaphus L., 1758). Для успешной реакклиматизации проводится передержка вселяемых животных в местах выпуска. Эта процедура осуществляется в специально созданных временных вольерах.
Вольер для передержки - огороженная часть территории, предназначенная для временного содержания диких животных, в том числе для вселения (включая расселение), интродукции, реинтродукции, акклиматизации, скрещивания и воспроизводства [1].

Резкое увеличение численности оленя благородного приводит к повышению нагрузки на подпологовую растительность лесных насаждений. Исследования по изучению влияния копытных 
на лесные фитоценозы в европейских странах ведутся как необходимые мониторинговые работы, позволяющие отслеживать уровень и характер влияния этой группы зверей на формирования лесной растительности, что крайне важно для своевременного решении вопросов взаимодействия в системе «копытные животные - лесные насаждения» [2].

В естественных условиях превышение численности животных влечет за собой уменьшение продукции пастбищ и в конечном итоге сказывается на состоянии животных и плотности их популяций в целом. Благодаря налаженным природным механизмам в условиях естественных экосистем численность диких фитофагов регулируется количеством доступной продукции фитоценозов [3]. Но при вольерном содержании эти механизмы не работают, так как животные ограничены в возможности передвижения и доступа к кормам. Сведения о характере влияния копытных на лесные насаждения, в том числе при их вольерном содержании, носят отрывочный характер [4].

Цель исследований заключалась в оценке состояния подпологовых ярусов лесных насаждений на территории вольеров для передержки в зависимости от временного периода, прошедшего с момента выпуска животных.

Основная часть. Территории, на которых были созданы вольеры для передержки животных, не выводятся из постоянного назначения и в дальнейшем должны выполнять свои основные первоначальные функции. После выпуска животных в местах создания вольеров не производится качественная оценка включенных ранее в их состав земель, в том числе не оценивается состояние лесных насаждений. Если на сельскохозяйственных землях достаточно быстро происходят процессы восстановления травянистой растительности, то в лесных насаждениях может наблюдаться частичное снижение их устойчивости к факторам внешней среды, в этот период они могут подвергнуться воздействию энтомои фитовредителей.

Исследования были выполнены в насаждениях на территориях вольеров, выпуск животных из которых проводился в текущем году, три и пять лет назад (табл. 1). Все эти вольеры ис- пользовались для передержки животных дважды, с незначительными перерывами. Насаждения на территории вольеров сходны по своему составу и возрасту, с преобладанием сосняков, которые занимают до $80 \%$ включенных в состав вольеров лесных земель. В сосновых насаждениях примесь мелколиственных пород составляет до $30 \%$. Для оценки происходящих в насаждениях изменений закладывались пробные площади по общепринятым в лесоведении, лесоводстве и лесной таксации методикам [5].

На пробных площадях закладывались трансекты, на которых производился сплошной перечет всех растений из ярусов подроста и подлеска (по стволикам) с распределением по высотам, степени и характеру повреждений.

По результатам обследования подроста и подлеска устанавливались следующие показатели [6]:

$A$ - общее количество подроста и подлеска по породам на всех трансектах, экз.;

$B$ - общее количество поврежденных экземпляров подроста и подлеска по породам, экз.;

$C$ - общее количество экземпляров всех древесных и кустарниковых пород на всех трансектах, эКз.

На основании этих величин определяли показатели:

1) частота встречаемости $(S)$ каждой породы

$$
S=\frac{n 100}{N} \%,
$$

где $n$ - число трансект, на которых встречена каждая порода;

$N$ - общее количество трансект;

2) обилие каждой породы $(G)$

$$
G=\frac{A 100}{C} \% ;
$$

3) повреждаемость (предпочтительность) $(P)$ каждой породы

$$
P=\frac{B 100}{A} \% .
$$

Все растения из числа подроста и подлеска делились на пять категорий: здоровые, слабо поврежденные, средне поврежденные, сильно поврежденные, погибшие [5].

Таблица 1

Характеристика вольеров для передержки охотничьих животных

\begin{tabular}{|l|c|c|c|}
\hline \multicolumn{1}{|c|}{ Объект } & $\begin{array}{c}\text { Площадь, } \\
\text { га }\end{array}$ & $\begin{array}{c}\text { Год последнего } \\
\text { выпуска }\end{array}$ & $\begin{array}{c}\text { Средняя плотность, } \\
\text { особей/га }\end{array}$ \\
\hline Учреждение «Минская РОС» РГОО «БООР» & 5,4 & 2016 & 13,0 \\
\hline Учреждение «Смолевичская РОС» РГОО «БООР» & 38,0 & 2016 & 2,4 \\
\hline Учреждение «Червенская РОС» РГОО «БООР» & 7,4 & 2018 & 3,1 \\
\hline Учреждение «Вилейская РОС» РГОО «БООР» & 12,0 & 2020 & 3,5 \\
\hline Учреждение «Пуховичская РОС» РГОО «БООР» & 12,4 & 2021 & 2,8 \\
\hline
\end{tabular}

Труды БГТУ Серия 1 № 12022 
В естественных условиях обитания основу рациона оленя благородного (Cervus elaphus L., 1758) при отсутствии в достаточном количестве травянистых растений составляют кора, молодые побеги и почки ясеня, осины, несколько менее предпочитаемы - дуба, липы, сосны и других пород [7]. Повреждаются животными в основном молодые побеги, реже стволики кормовых растений на высоте до 2 м. Около 5$15 \%$ в общем объеме питания древесно-веточными кормами занимают такие породы, как рябина обыкновенная (Sorbus aucuparia L., 1753), черемуха обыкновенная (Padus racemosa G., 1782), бересклеты (Euonymus verrucosa S., E. europaca L.). Повреждаются они чаще других древесных и кустарниковых растений, так как являются излюбленным кормом оленей. При этом животные повреждают как ветви, так и стволики растений. В естественных условиях обитания животные практически не повреждают ель обыкновенную (Pinus abies L., 1753) [7].

Проведенные исследования показывают, что в условиях вольеров для передержки, характеризующихся высокой плотностью населения животных, происходит повреждение всех древесных и кустарниковых растений в зоне потрав, независимо от кормовых предпочтений животных.

С хозяйственной точки зрения после древесного яруса наибольшую ценность представляет собой подрост как молодое поколение леса, которое в будущем, способно сформировать древостой. В насаждениях на пробных площадях отмечено от пяти до семи видов древесных растений в составе подроста (табл. 2).
Из встреченных нами повреждений наиболее распространенными являются объедания молодых побегов растений и коры стволиков, в меньшей степени распространены механические повреждения (заломы, затесы коры). Худшее жизненное состояние подроста, сохранившегося на пробных площадях, наблюдается в год выпуска животных из вольера. С течением времени происходит постепенное восстановление этого яруса. Данный процесс идет по двум направлениям: восстановление подвергнухшихся воздействию со стороны животных растений, а также нами отмечено появление молодых растений. Наибольшей скоростью восстановления отличаются поврежденные растения березы повислой (Betula pendula Roth., 1788) и осины (Populus tremula L., 1753), что обусловлено их биологическими особенностями. Вместе с тем даже спустя пять лет после выпуска оленей из вольеров сохранившиеся растения имеют следы воздействия животных. Из состава подроста полностью выпадает сосна обыкновенная (Pinus sylvestris L., 1753).

Минерализация почвы, некоторое увеличение освещенности способствуют появлению через три - пять лет после выпуска животных молодого поколения осины и березы как вегетативного, так и семенного происхождения.

На всех исследуемых территориях встречался подрост ели. Прослеживается выраженная закономерность между обилием растений этой породы и их жизненным состоянием. Так, растения, встречающиеся в насаждениях на пробных площадях единично или достаточно редко, имели наибольшие повреждения оленями.

Таблица 2

Оценка состояние подроста в насаждениях на пробных площадях

\begin{tabular}{|c|c|c|c|c|c|c|c|c|c|c|c|c|}
\hline \multirow{3}{*}{ Порода } & \multicolumn{12}{|c|}{ Показатели } \\
\hline & \multicolumn{4}{|c|}{ год выпуска животных } & \multicolumn{4}{|c|}{$\begin{array}{c}3 \text { года после выпуска } \\
\text { животных }\end{array}$} & \multicolumn{4}{|c|}{$\begin{array}{c}5 \text { лет после выпуска } \\
\text { животных }\end{array}$} \\
\hline & $S$ & $G$ & $P$ & K & $S$ & $G$ & $P$ & $K$ & $S$ & $G$ & $P$ & $K$ \\
\hline $\begin{array}{l}\text { Осина (Populus tremula } \\
\text { L., 1753) }\end{array}$ & 12,2 & 6,2 & 100 & 4,4 & 66,7 & 18,4 & 81,5 & 3,03 & 36,8 & 22,1 & 57,1 & 2,3 \\
\hline $\begin{array}{l}\text { Береза повислая (Betula } \\
\text { pendula Roth., 1788) }\end{array}$ & 22 & 21,1 & 78,6 & 4,1 & 76,2 & 29,7 & 69,4 & 3,33 & 44,7 & 37,8 & 48,1 & 1,9 \\
\hline $\begin{array}{l}\text { Ясень обыкновенный } \\
\text { (Fraxinus excelsior L., 1753) }\end{array}$ & 9,8 & 1,4 & 100 & 4 & 0 & 0 & 0 & 0 & 0 & 0 & 0 & 0 \\
\hline $\begin{array}{l}\text { Сосна обыкновенная } \\
\text { (Pinus sylvestris L., 1753) }\end{array}$ & 63,4 & 38,1 & 100 & 4,5 & 57,1 & 24,8 & 100 & 4,5 & 52,6 & 11,2 & 100 & 4,7 \\
\hline $\begin{array}{l}\text { Ель европейская (Pinus } \\
\text { abies L., 1753) }\end{array}$ & 41,5 & 23,6 & 100 & 3,7 & 38,1 & 21,1 & 100 & 3,7 & 34,2 & 14,8 & 100 & 3,6 \\
\hline $\begin{array}{l}\text { Клен остролистный (Acer } \\
\text { platanoides L., 1753) }\end{array}$ & 12,2 & 0,4 & 100 & 3,8 & 0 & 0 & 0 & 0 & 0 & 0 & 0 & 0 \\
\hline $\begin{array}{l}\text { Дуб обыкновенный (Quer- } \\
\text { cus robur L., 1753) }\end{array}$ & 43,9 & 9,2 & 100 & 4,6 & 14,3 & 6 & 83,3 & 3,9 & 18,4 & 14,1 & 61,7 & 3,1 \\
\hline
\end{tabular}


На пробных площадях отмечено от 5 до 7 видов растений в составе подлеска (табл. 3). Наиболее распространенными являются следующие: крушина ломкая (Frángula álnus Mill., 1768) и рябина (Sórbus aucupária L., 1753), единично встречаются ирга круглолистная (Amelánchier ovális Medik.) и черемуха обыкновенная (Padus racemo$s a$ G., 1782). Высота подлеска в год после выпуска составляла 1,47 м. Спустя 5 лет после выпуска животных средняя высота подлеска уменьшается до 1,12 м, что связано с большим количеством растений крушины ломкой (Frángula álnus Mill., 1768) и рябины (Sórbus aucupária L., 1753) высотой до 0,5 м, относящихся к молодому поколению.

Можжевельник обыкновенный (Juniperus commúnis L., 1753) был встречен нами только в насаждениях в вольерах, выпуск из которых был произведен в текущем году. Все растения имели следы интенсивных повреждений животными. В насаждениях на объектах, выпуск из вольеров которых состоялся 3 и 5 лет назад, можжевельник не встречался, что может быть обусловлено гибелью растений вследствие воздействия со стороны оленей благородных (Cervus Elaphus L., 1758). Таким образом, несмотря на интенсивное воздействия, которое испытывает подлесочная растительность, в насаждениях спустя 3-5 лет после выпуска оленей благородных происходит ее достаточно быстрое восстановление, что обусловлено высокой устойчивостью лиственных растений к механическим повреждением и способностью давать обильные корневые отпрыски.

Живой напочвенный покров также испытывает интенсивное воздействие со стороны животных: частично растения используются в пищу, частично - вытаптываются. Одним из наиболее привлекательных кормовых растений в составе живого напочвенного покрова для оленя благородного (Cervus Elaphus L., 1758) является черника (Vaccínium myrtillus L., 1753). Состояние этого растения можно использовать как индикатор для характеристики изменений, происходящих в живом напочвенном покрове в целом. В период содержания оленей в вольере наблюдается сильное объедание растений черники, что приводит к сокращению ее проективного покрытия (табл. 4). На территории вольеров наблюдается увеличение плотности почвы, особенно около биотехнических объектов, а также вдоль ограждений, что негативно сказывается на состоянии подпологовой растительности и в наибольшей степени - живого напочвенного покрова.

Таблица 3

Оценка состояния подлеска в насаждениях на пробных площадях

\begin{tabular}{|c|c|c|c|c|c|c|c|c|c|c|c|c|}
\hline \multirow{3}{*}{ Порода } & \multicolumn{12}{|c|}{ Показатели } \\
\hline & \multicolumn{4}{|c|}{$\begin{array}{c}\text { исследование в год выпуска } \\
\text { животных }\end{array}$} & \multicolumn{4}{|c|}{$\begin{array}{c}\text { результаты через } 3 \text { года } \\
\text { после выпуска животных }\end{array}$} & \multicolumn{4}{|c|}{$\begin{array}{c}\text { результаты через } 5 \text { лет } \\
\text { после выпуска животных }\end{array}$} \\
\hline & $S$ & $G$ & $P$ & $K$ & $S$ & $G$ & $P$ & $K$ & $S$ & $G$ & $P$ & $K$ \\
\hline $\begin{array}{l}\text { Ива козья (Salix } \\
\text { caprea L., 1753) }\end{array}$ & 10,5 & 4,8 & 100 & 4,3 & 13,2 & 5,1 & 100 & 4 & 5,3 & 1,2 & 100 & 3,7 \\
\hline $\begin{array}{l}\text { Крушина ломкая } \\
\text { (Frangula alnus } \\
\text { Mill., 1768) }\end{array}$ & 81,6 & 54,8 & 100 & 4,8 & 42,1 & 64,5 & 88,6 & 3,6 & 47,4 & 72 & 30,1 & 2,7 \\
\hline $\begin{array}{lr}\text { Рябина } & \text { обыкно- } \\
\text { венная } & \text { (Sorbus } \\
\text { aucuparia } & \text { L., 1753) }\end{array}$ & 76,3 & 27,6 & 100 & 4,8 & 26,3 & 9,2 & 88,1 & 3,2 & 52,6 & 21,2 & 48,2 & 2,9 \\
\hline $\begin{array}{l}\text { Бересклет бородав- } \\
\text { чатый (Euonymus } \\
\text { verrucosus Scop.) }\end{array}$ & 2,6 & 0,4 & 100 & 4 & 2,6 & 0,7 & 100 & 4 & 0 & 0 & 0 & 0 \\
\hline $\begin{array}{l}\text { Ирга круглолист- } \\
\text { ная (Amelanchier } \\
\text { ovalis Medik.) }\end{array}$ & 0 & 0 & 0 & 0 & 5,3 & 0,2 & 100 & 4 & 10,5 & 1,2 & 18,5 & 1,2 \\
\hline $\begin{array}{l}\text { Черемуха обык- } \\
\text { новенная (Padus } \\
\text { racemosa G., 1782) }\end{array}$ & 5,3 & 1,1 & 100 & 4,1 & 0 & 0 & 0 & 0 & 2,6 & 2,3 & 94,1 & 2,4 \\
\hline $\begin{array}{l}\text { Смородина черная } \\
\text { (Ribes nigrum L., 1753) }\end{array}$ & 2,6 & 0 & 100 & 4,2 & 15,8 & 14,8 & 95,5 & 3,7 & 0,0 & 0 & 0 & 0 \\
\hline $\begin{array}{l}\text { Можжевельник обык- } \\
\text { новенный (Juniperus } \\
\text { communis L., 1753) }\end{array}$ & 2,6 & 0,9 & 100 & 4,1 & 5,3 & 0,7 & 100 & 3,3 & 0 & 0 & 0 & 0 \\
\hline $\begin{array}{l}\text { Лещина обыкно- } \\
\text { венная (Corylus } \\
\text { avellana L., 1753) }\end{array}$ & 63,2 & 10,4 & 100 & 4 & 23,7 & 4,8 & 81,8 & 2,7 & 18,4 & 2,1 & 87,2 & 1,9 \\
\hline
\end{tabular}


Оценка проективного покрытия и жизненного состояния черники в насаждениях на пробных площадях

\begin{tabular}{|l|c|c|c|c|c|}
\hline Показатель & $\begin{array}{c}\text { Учреждение } \\
\text { «Пухович- } \\
\text { ская РОС» } \\
\text { РГОО } \\
\text { «БООР» }\end{array}$ & $\begin{array}{c}\text { Учреждение } \\
\text { «Вилейская } \\
\text { РОС» } \\
\text { «БООР }\end{array}$ & $\begin{array}{c}\text { Учреждение } \\
\text { «Червен- } \\
\text { ская РОС» } \\
\text { РГОО } \\
\text { «БООР» }\end{array}$ & $\begin{array}{c}\text { Учреждение } \\
\text { «Смолевич- } \\
\text { ская РОС» } \\
\text { РГОО «БООР» }\end{array}$ & $\begin{array}{c}\text { Учрежде- } \\
\text { ние «Мин- } \\
\text { ская РОС» } \\
\text { РГОО } \\
\text { «БООР» }\end{array}$ \\
\hline Проективное покрытие, \% & 2,1 & 2,3 & 7,5 & 20,1 & 20,4 \\
\hline Жизненное состояние, балл & 3,9 & 4,1 & 2,7 & 1,7 & 1,8 \\
\hline
\end{tabular}

Заключение. Лесные насаждения при кратковременном вольерном содержании в условиях высокой плотности оленей испытывают интенсивное воздействие со стороны животных. Наиболее подвержены этому воздействию подрост, подлесок, живой напочвенный покров. В ярусе подроста происходит гибель практически всех молодых деревьев сосны (Pinus sylvestris L., 1753), частично погибают подрост осины (Populus tremula L., 1753), дуба (Quercus robur L., 1753), клена (Acer platanoides L., 1753). Из подлесочного яруса в наибольшей степени повреждаются крушина (Frángula álnus Mill., 1768), рябина (Sórbus aucupária L., 1753) и ива козья (Salix caprea L., 1753).

Для содержащихся в вольерах оленей благородных наиболее привлекательным в кормовом отношении растением в живом напочвенном покрове является черника (Vaccínium myrtillus L., 1753). При вольерном содержании наблюдается значительное сокращение проективного покрытия этого растения, однако после выпуска животных происходит ее разрастание.

Содержание животных приводит к некоторой минерализации почвы и уплотнению в местах биотехнических сооружений и по периметру территории вольера. С течением времени наблюдается постепенное восстановление подпологовой растительности в насаждениях на пробных площадях. В ярусе подроста во многом благодаря минерализации почвы происходит увеличение количества молодых растений березы повислой (Betula pendula Roth., 1788) и осины (Populus tremula L., 1753), разрастание подлесочного яруса.

\section{Список литературы}

1. Положение о порядке создания вольеров, установления ограничений и запретов на их создание, содержания, разведения и использования в них диких животных, в том числе проведения вольерной охоты [Электронный ресурс]: постановление Совета Министров Респ. Беларусь, 27.06.2018 № 493 // ЭТАЛОН / Нац. центр правовой информ. Респ. Беларусь. Минск, 2018.

2. Angelstam P., Wikberg P. E., Danilov P., Faber W. E, Nygren K. Effects of moose density on timber quality and biodiversity restoration in Sweden, Finland, and Russian Karelia. Alces. 2000. Vol. 36. P. 133-145.

3. Абатуров Б. Д., Магомедов М.-Р. Д. Факторы трофической обусловленности динамики и устойчивости популяций растительноядных млекопитающих // Экология популяций. 1988. С. 5-7.

4. Шакун В. В., Козорез А. И., Кудин М. В. Состояние и задачи исследований ресурсов охотничьей фауны Беларуси // Современные проблемы охотоведения и сохранения биоразнообразия: материалы Междунар. науч.-практ. конф., посвященной 90-летию со дня рождения В. С. Романова, Минск, 16-17 мая 2017 г. Минск: БГТУ, 2017. С. 169-174.

5. Площади пробные лесоустроительные. Метод закладки: ОСТ 56-69-83. Введ. 01.06.83. М.: Изд-во стандартов, $1983.56 \mathrm{c}$

6. Романов В. С., Козло П. Г., Падайга В. И. Охотоведение: учебник. Минск: Тесей, 2005. 448 с.

7. Шакун В. В., Панченко Д. В., Соловей И. А., Крищук И. А., Велигуров П., Машков Е., Ларченко А. Роль оленьих (Cervidae) в формировании сосновых насаждений европейской части южной тайги. Norwegian Journal of Development of the International Science. 2020. № 42-2. C. 13-19.

\section{Referens}

1. Regulations on the procedure for creating aviaries, establishing restrictions and prohibitions on their creation, keeping, breeding and using wild animals in them, including conducting aviary hunting Resolution of the Council of Ministers of the Republic of Belarus. No. 493 on 27.06.2018]. ETALON [National Center for Legal Information Republic of Belarus]. Minsk, 2018 (In Russian).

2. Angelstam P., Wikberg P. E., Danilov P., Faber W. E, Nygren K. Effects of moose density on timber quality and biodiversity restoration in Sweden, Finland, and Russian Karelia. Alces. 2000, vol. 36, pp. 133-145. 
3. Abaturov B. D., Magomedov M.-R. D. Factors of trophic conditionality of dynamics and stability of populations of herbivorous mammals. Ekolagiya populyatsiy [The population ecology], 1988, pp. 5-7 (In Russian).

4. Shakun V. V., Kozorez A. I. Kudin, M. V. State and tasks of the research resources hunting fauna of Belarus. Sovremennyye problemy okhotovedeniya i sokhraneniya bioraznoobraziya: materialy Mezhdunarodnoy nauchno-prakticheskoy konferentsii, posvyashchennoy 90-letiyu so dnya rozhdeniya $V$. S. Romanova [Modern problems of hunting and conservation: materials of the International Scientific and Practical Conference dedicated to the 90th anniversary of the birth of V. S. Romanova], 2017, pp. 169-174 (In Russian).

5. OST 56-69-83. Trial forest management areas. Bookmark method. Moscow, Publishing House of Standards Publ., 1983. 56 p. (In Russian).

6. Romanov V. S., Kozlo P. G., Padaiga V. I. Okhotovedeniye [Hunting studies]. Minsk, Tesey Publ., 2005. 448 p. (In Russian).

7. Shakun V. V., Panchenko D. V., Solovey I. A., Krischuk I. A., Veligurov P., Mashkov E., Larchenko A. The role of deer (Cervidae) in the formation of pine plantations in the European part of the southern taiga. Norwegian Journal of Development of the International Science. 2020, no. 42-2, pp. 13-19 (In Russian).

\section{Информация об авторах}

Митренков Андрей Михайлович - ассистент кафедры туризма, природопользования и охотоведения. Белорусский государственный технологический университет (220006, г. Минск, ул. Свердлова, 13a, Республика Беларусь). E-mail: mitrenkov@belstu.by

Бахур Олег Владимирович - кандидат биологических наук, доцент, доцент кафедры туризма, природопользования и охотоведения. Белорусский государственный технологический университет (220006, г. Минск, ул. Свердлова, 13а, Республика Беларусь). E-mail: oleg_bahur@belstu.by

\section{Information about the authors}

Mitrenkov Andrey Mikhaylovich - assistant lecturer, the Department of Tourism, Nature Management and Game Menagement. Belarusian State Technological University (13a, Sverdlova str., Minsk, 220006, Republic of Belarus). E-mail: mitrenkov@belstu.by

Bakhur Aleh Vladimirovich - PhD (Biology), Associate Professor, Assistant Professor, the Department of Tourism, Nature Management and Game Menagement. Belarusian State Technological University (13a, Sverdlova str., 220006, Minsk, Republic of Belarus). E-mail: oleg_bahur@belstu.by 